\title{
Correction to: Market competition and parental background wage premium: the role of human and relational capital
}

\author{
Maurizio Franzini $^{1}$ • Fabrizio Patriarca ${ }^{2}$. Michele Raitano ${ }^{1}$
}

Received: 01 September 2020 / Accepted: 01 September 2020 /Published online: 12 September 2020

(C) Springer Science+Business Media, LLC, part of Springer Nature 2020

\section{Correction to: The Journal of Economic Inequality (2020) 18:291-317 https://doi.org/10.1007/s10888-020-09441-y}

The original article unfortunately contains error in figure captions.

The corrected figure captions should be.

Fig. $290 \%$ confidence interval of the estimated coefficient of the association between log of gross weekly wage from private employment and the interaction between children's and parents' educational attainment and sectorial import penetration. Full sample. Random effects estimates ${ }^{1}$

Fig. $390 \%$ confidence interval of the estimated coefficient of the association between log of gross weekly wage from private employment and the interaction between children's and parents' educational attainment and sectorial import penetration. Full sample. Fixed effects estimates ${ }^{1}$

Publisher's Note Springer Nature remains neutral with regard to jurisdictional claims in published maps and institutional affiliations.

The online version of the original article can be found at https://doi.org/10.1007/s10888-020-09441-y

Michele Raitano

michele.raitano@uniroma1.it

Maurizio Franzini

maurizio.franzini@uniroma1.it

Fabrizio Patriarca

fabrizio.patriarca@unimore.it

1 Department of Economics and Law, Sapienza University of Rome, Via del Castro Laurenziano 9, 00161 Rome, Italy

2 Department of Economics "Marco Biagi", University of Modena and Reggio Emilia, viale Berengario 51, 41121 Modena, Italy 